\title{
School Values: A Comparison of Academic Motivation, Mental Health Promotion, and School Belonging With Student Achievement
}

Kelly-Ann Allen, Margaret L. Kern, Dianne Vella-Brodrick and Lea Waters

The University of Melbourne, Australia

\begin{abstract}
School vision and mission statements are an explicit indication of a school's priorities. Research has found academic motivation, mental health promotion, and school belonging to be the most frequently cited themes in these statements. The present study sought to examine whether these themes relate to student academic achievement, as indicated by National Assessment Program - Literacy and Numeracy (NAPLAN) scores. A stratified sample of 287 secondary schools in Victoria, Australia was analysed using two language analytic approaches: qualitative emergent coding and supervised lexical analysis. The highest academic scores occurred when mental health promotion was included, though results depended to some extent on the analytic approach and the level of aggregation. Results do suggest that explicitly prioritising both academic performance and mental health is beneficial. Further, the study provides an approach for using language analysis to investigate multilevel constructs in schools.
\end{abstract}

Keywords: academic achievement, mental health promotion, school belonging, lexical analysis, mixed methods

A central function of schools is to equip students with knowledge and skills that will help them succeed in life. The most quantifiable method to determine whether this function has been achieved is through grades, assessments, and performance on standardised tests (Australian Curriculum Assessment and Reporting Authority [ACARA], 2008). As such, quantified measures of academic achievement are generally considered to be the gold standard indication of school success (Pollock \& Winton, 2012; Stemler, Bebell, \& Sonnabend, 2011). However, many schools also value student wellbeing, school belonging (Allen, Kern, Waters, \& Vella-Brodrick, 2016; Quinlan, Swain, Cameron, \& Vella-Brodrick, 2014), and civic, emotional, and cognitive development (Stemler et al., 2011).

Received 15 February 2017; Accepted 12 May 2017; First published online 13 June 2017

Address for correspondence: Kelly Allen, Melbourne Graduate School of Education, The University of Melbourne, 234 Queensberry Street, Parkville VIC 3053, Melbourne, Australia. Email: kellya@toorakc. vic.edu.au. 
Most research investigating student wellbeing has focused on student level data (e.g., Reitzner, 2014). Yet, numerous factors across multiple socioecological levels have an impact on student wellbeing, including peers, families, teachers, neighbourhoods, school climate, policies, laws, and cultural norms (Allen, Vella-Brodrick, \& Waters, 2016; Allen, Kern, Vella-Brodrick, Hattie, \& Waters, 2016). Organisational features of a school, such as the structures, goals, policies, and norms, play an important role in creating a climate that either promotes or impedes wellbeing (Swearer et al., 2006).

One such organisational feature is the vision or mission statement (VMS) of the school. Most schools have such a statement, which explicitly outlines the school's purpose, values, and priorities. The current study assesses whether there is a relationship between the degree to which schools prioritise academic achievement and wellbeing, as indicated by their VMSs, and the academic achievements of their students, as measured by National Assessment Program — Literacy and Numeracy (NAPLAN) results.

\section{School Vision and Mission Statements and Achievement}

It has been argued that VMSs provide schools with direction (Allen, Vella-Brodrick et al., 2016). They 'arise from a set of values that answer fundamental questions about the purpose of education and how the educational programs should be carried out' (Boerema, 2006, p. 182) and typically define the physical, social, and political contexts that govern an institution. According to Fritz (1996), VMSs exist to aid school improvement and provide insight into the daily operations of the school. Jones and Crochet (2007) consider VMSs vital for school improvement, as they identify desired functional levels, provide a framework for decision making and actions, promote staff teamwork, and frame the goals that are set for the future.

School VMSs generally include both academic aspects and a range of other values including academic motivation, mental health promotion, school belongingness, teacher support, and personal character (Allen, Kern et al., 2016; Stemler \& Bebell, 1999; Wilkerson, 2010). Only a handful of studies have subsequently linked these values to student outcomes. Brown, Choi, and Herman (2011) examined 34 independent schools in Texas that employed the Courageous Leadership Academy (CLA) a school reform model that uses the development of core mission, vision, values, and goals as a central function. There was a strong relationship between the quality of implementation and student achievement. Davis, Ruhe, Lee, and Rajadhyaksha (2007) sampled students across 16 universities to investigate whether the use of ethical content in a VMS reflected students' ethical orientation. Findings suggested that student character was affected by the traits that were reinforced in the VMSs, especially in relation to heart traits (associated with ethical behaviour), confidence, and learning. While the causality of these relationships cannot be determined (i.e., whether VMSs influence the character of the students within an institution, or students choose institutions that match their orientation, or a range of other confounding factors), these findings support the potential usefulness of VMSs within educational settings.

The use of VMSs by organisations is sometimes met with criticism. A central concern is their use in marketing and promotion campaigns, which raises questions regarding their applied and measurable impact in schools. For example, although a vision and mission statement may explicitly imply that a school prioritises the social and emotional development of students, that priority is not necessarily carried through in the implicit culture of the school. Still, some evidence suggests that when VMSs are 
well written, transparent, and void of fashionable statements, their values are often reflected in the actual practices of a school (Chapple, 2015; Manley \& Hawkins, 2009; Stemler et al., 2011). Moreover, a VMS, irrespective of whether or not it is applied to daily practices, can still indicate what the school may aspire to (Stemler et al., 2011). Thus, while it is beyond the scope of this article to evaluate whether or not schools actually implement the priorities noted in their statements, there still is value in considering the potential impact of VMSs on academic outcomes.

\section{School Values and Academic Achievement}

Allen, Kern et al. (2016) analysed the VMSs of secondary schools in Victoria, Australia, and identified 10 common themes: academic motivation, personal characteristics, school belonging, teacher support, other support, mental health promotion, the school environment, Christianity, future focus, and individual needs. While academic motivation was the most frequent theme, over half of the schools also included mental health promotion (MHP) and school belonging. In the current analysis, we examine the extent to which these three themes relate to academic achievement.

Academic motivation and academic achievement. Academic motivation has been conceptualised in multiple ways, but is generally concerned with the 'extent to which students are motivated to learn and do well in school' (Libbey, 2004, p. 278), Lee, McInerney, Liem, and Ortiga (2010) define motivation as 'an internal state that instigates, directs, and maintains behaviour' (p. 264). The concept of motivation is best explained by one of the most dominant theories of motivation, self-determination theory (SDT; Ryan \& Deci, 2000). SDT suggests that behaviours and cognitions are affected by one's source of motivation, which runs on a continuum from intrinsic motivation (internally driven; e.g., personal goals) to extrinsic motivation (externally driven; e.g., through rewards) to amotivation (absence of motivation). SDT explicitly includes both cognitive and behavioural components. Thus, academic motivation incorporates cognitions such as planning and setting goals, and behaviours such as the act of pursuing those goals and achieving higher levels of performance. For instance, DiPerna, Volpe, and Elliot (2002) found that academic skills and competence (cognitions) related to better study skills and greater school engagement (behaviours), which in turn resulted in higher academic achievement.

As motivation becomes increasingly internalised, better performance often occurs (e.g., DiPerna et al., 2002; Robbins et al., 2004). For instance, with 450 adolescents in Nigeria, academic motivation had a significant positive impact on secondary school students' mathematic scores (Tella, 2007). A meta-analysis of 109 studies, which defined academic motivation as being internal in nature (e.g., academic discipline, commitment, determination, and goal striving), found that motivation was highly correlated with high school and college grade point average, beyond all other factors investigated, including social support and socio-economic status (Robbins et al., 2004).

In the current study, statements within the VMSs reflect the cognitive element, and academic performance reflects the behavioural component of academic motivation. VMSs often present an ideal vision for students and the school as a whole and thus reflect more internalised forms of motivation, with statements such as 'We aim to develop imaginative, innovative thought and independent critical thinking' (Allen, Kern et al., 2016). 
Mental health promotion and academic achievement. MHP is defined as proactively protecting and optimising mental health through enhancing strengths and capabilities, as opposed to reactively addressing mental-health disorder (Allen \& McKenzie, 2015; Donovan, James, Jalleh, \& Sidebottom, 2006; Kobau et al., 2011). At the school level, MHP may exist through mental health promotion campaigns, social-emotional learning programs, and the implementation of collaborative services that nurture holistic wellness (Rickwood, 2007).

It is well established in the literature that adolescents who experience mental health concerns during secondary school are at an educational disadvantage across a range of measures, including achievement (e.g., Greenberg et al., 2003; Zins, Weissberg, Wang, \& Walberg, 2004). Durlak, Weissberg, Dymnicki, Taylor, and Schellinger (2011) presented the strongest evidence for MHP, by conducting a meta-analysis of 213 social and emotional learning programs involving over 270,000 students, finding that such programs were significantly and positively associated with higher levels of achievement, potentially boosting test scores by as much as 11 percentile points. This finding has been supported by other large reviews and syntheses of the literature (e.g., the Collaborative for Academic Social and Emotional Learning [CASEL], 2007; Payton et al., 2008). In Australia, Dix, Slee, Lawson, and Keeves (2012) investigated 260 schools employing the whole school mental health promotion initiative, KidsMatter. Across a 2-year period, schools that implemented KidsMatter improved their NAPLAN scores at an equivalent of 6 months' additional schooling. Slee et al. (2009) found that most teachers agreed that students who are socially and emotionally competent learn more.

School belonging and academic achievement. School belonging refers to an affective experience by students that involves a sense of connectedness or affiliation towards the school. A sense of school belonging is influenced by individual (e.g., academic motivation and self-efficacy), relational (e.g., perceived relationships with teachers and peers), and organisational (e.g., policies and practices concerned with safety) factors within a school setting (Allen, Vella-Brodrick et al., 2016).

Studies suggest that a significant positive relationship exists between school belonging and academic achievement, both cross-sectionally and longitudinally (Benner, Graham, \& Mistry, 2008; Bonny, Britto, Klostermann, Hornung, \& Slap, 2000; Mo \& Singh, 2008; Wilkinson-Lee, Zhang, Nuno, \& Wilhelm, 2011; Sirin \& Rogers-Sirin, 2004, 2005). For example, Sirin and Rogers-Sirin (2004) found school belonging to be one of the strongest predicators of academic performance in their sample of 336 African-American students. A second study found similar findings, even after controlling for gender, year level, cognitive functioning, and the educational background of parents (Sirin \& Rogers-Sirin, 2005). Across 572 young people, GillenO'Neel and Fuligni (2013) found that school belonging was associated with a higher level of academic motivation across a 4-year period. Moreover, the Wingspread Declaration on School Connections (2004) presented evidence that school belonging increases classroom engagement, which is considered to be an element of academic motivation (e.g., Connell \& Wellborn, 1991; Croninger \& Lee, 2001; Klem \& Connel, 2003). Additional support for such findings appear throughout the literature (e.g., Battistich, Solomon, Kim, Watson, \& Schaps, 1995; Roeser, Midgley, \& Urdan, 1996). 
Measuring Academic Outcomes

Although academic success can be conceptualised and measured in different ways, NAPLAN is currently the dominant outcome of interest in Australia (Guenther, 2013; Miller \& Voon, 2012; Polesel, Dulfer, \& Turnbull, 2012; Quinell \& Carter, 2011). NAPLAN is an annual assessment test undertaken by Australian students in Years 3, 5, 7, and 9. It is managed by ACARA, an independent body established by the Australian Government for the purpose of data collection, assessment, and curriculum implementation (Dix et al., 2012). NAPLAN is administered nationally each year in government, independent, and Catholic schools. The test assesses four domains: reading, writing, language conventions (spelling, grammar, and punctuation), and numeracy, and provides standardised information on student performance across these areas. Average scores for each school are publicly available (http://www.myschool.edu.au), while the data for individual students is only released to the school (Miller \& Voon, 2012; Thompson, 2013).

NAPLAN and other standardised tests such as the Scholastic Aptitude Test (SAT) in the United States have been criticised for reducing the complexity of teaching practice to a set of numbers (Hardy \& Boyle, 2011). It imposes a one-size-fits-all model, which disadvantages minority groups (Guenther, 2013; Wigglesworth, Simpson, \& Loakes (2011). Other criticisms of NAPLAN include possible narrowing of curriculum, manipulation of data, reduction of breadth subjects (e.g., arts, humanities, physical education), and undue stress in young people (Anderson, 2009; Comber, 2012; Comber \& Nixon, 2009; Lingard, 2010; Thompson \& Cook, 2014). 'Cheating and gaming' can occur particularly when many stakeholders (e.g., government, parents, teachers) are interested in the results (Brown \& Hattie, 2012). Further, the validity of the numeracy tests have been questioned for using loaded language and vocabulary likely to confound students' performance (Quinell \& Carter, 2011).

Despite these criticisms, standardised tests continue to be considered the primary measures of academic performance (Volante, 2004). When used properly, NAPLAN can aid educators in determining students' strengths, achievement, growth, weaknesses, and decrements (Brown \& Hattie, 2012; Holmes, 2010; McMillan, 2000, Thompson, 2013). For better or worse, NAPLAN results are used to inform educators, parents, and guardians about a student's progress in the areas of literacy and numeracy (Quinell \& Carter, 2011) and is also used for accountability purposes on a national level.

\section{The Current Study}

Most studies linking academic motivation, MHP, and school belonging with academic outcomes have focused on individual students. While motivation, mental health, and school belonging are internal characteristics of the students, the school environment plays an important role in creating a climate that is more or less conducive to wellbeing (Allen, Kern et al., 2016). Although there will always be individual variation within the school, on average, academic performance might be better in more supportive environments. If VMSs do indeed guide the priorities, policies, and implicit and explicit norms of the school, then the question becomes the extent to which the values align with desired outcomes across the school as a whole.

In the current study, we examined associations between the presence of academic motivation, MHP, and school belonging themes within VMSs and academic 
achievement, operationalised as average NAPLAN scores. Based on the significant and positive relationship between academic achievement and these three variables found in past literature at the student level, we hypothesised that greater endorsement of academic motivation, MHP, or school belonging would be positively related to academic achievement at the school level. Further, due to the importance of social and emotional factors, we hypothesised that emphasising MHP or school belonging along with academic motivation (i.e., explicitly prioritising both the academic and socio-emotional characteristics of students) would relate to the highest NAPLAN scores, compared to schools that do not include these social and emotional factors in their VMSs.

\section{Method}

\section{Participants}

We used a set of VMSs from secondary schools in Victoria, Australia, compiled by Allen, Kern et al. (2016). Across 579 secondary schools, a sample of 308 schools, stratified by school type (government, independent, Catholic), gender composition (all boys, all girls, co-educational), and location (urban, rural) was randomly selected. In January 2012, Allen, Kern et al. (2016) sourced VMSs directly from each individual school's publicly available website. Where a VMS was not publicly available, schools were directly contacted (see Allen, Kern et al. for further details regarding data collection).

Of the 308 schools, Year 7 and/or Year 9 NAPLAN data were available for 287 schools. Missing NAPLAN data were primarily due to the school being newly founded, closed down, amalgamated with another school, or not having Years 7 or 9 at their school. The sample included government $(n=158)$, independent $(n=75)$, and Catholic $(n=54)$ schools from urban $(n=162)$ and rural $(n=125)$ settings, with co-educational $(n=245)$, boys $(n=13)$ and girls $(n=29)$ gender compositions.

Obtaining a general achievement score. NAPLAN data were chosen due to their public availability for most schools, which enabled comparisons to be made across as many schools as possible. NAPLAN data for Year 7 and Year 9 students were obtained on request from ACARA for 2012, matching the year that the school vision and mission statements were collected. The domains of Grammar and Punctuation, Numeracy, Persuasive Writing, Reading, and Spelling are highly correlated (e.g., $r>.93)$, and when combined, create a reliable single achievement factor $(\alpha=.90)$ (Dix et al., 2012). As such, in the present study, we combined the five NAPLAN domains to create a general achievement score (Year 7: $\alpha=.97$, Year 9: $\alpha=.90$ ). The number of students within each school with Year 7 and 9 NAPLAN data was also recorded (total $N=$ 34,$409 ; M=120, S D=91.46$, range $=5-630$ ).

\section{Identifying Themes}

We used two approaches to determine whether academic motivation, MHP, and school belonging were present within each statement: a manual coding approach, typically used in qualitative research, and a supervised word count approach, used in quantitative research.

First, through an emergent coding approach, Allen, Kern et al. (2016) rated the occurrence of each theme in the statements. Ten major themes and a number of subthemes within the VMSs were identified and coded by two independent researchers 
(interrater reliability: $\chi=.81$ ). With emergent coding, categories are established following the preliminary examination of the data and then the researcher(s) seeks to examine these themes through an iterative process. Allen, Kern et al. used a coding rubric containing 10 major themes, each with a varying number of subthemes. Aligned with other studies (e.g., Stemler et al., 2011), themes were classified as major if they were mentioned by at least $20 \%$ of the schools, and variants classified by fewer schools were classified as subthemes. Based on these ratings, we used a dichotomous indicator of the overall academic motivation, MHP, and school belonging themes being present (coded 1) or absent (coded 0 ).

Second, we used a supervised lexical analysis approach. In lexical methods, a priori categories (or dictionaries) are developed based upon theory, and then the relative frequencies (i.e., total occurrence adjusted by the number of words) that those categories occur are automatically counted (see Kern et al., 2016, for an overview of the methodology and consideration of this approach). The most commonly used lexica approach in the social sciences is the Linguistic Inquiry and Word Count (LIWC) program, developed by Pennebaker, Chung, Ireland, Gonzales, and Booth (2007), which includes over 100 dictionaries (e.g., positive emotion, family, pronouns).

As no existing lexica adequately captured the three themes, we developed three new lexica. Drawing on descriptions and definitions of each theme from the literature, we listed relevant words and two to three word phrases (e.g., teacher support). We added relevant words from the LIWC dictionaries, and consulted with other researchers to identify additional relevant terms. We next examined sample cases where the words from the lexicon occurred, to ensure we captured the correct context. For example, for Academic Motivation, the word 'motivation' was only used once and did reflect motivation for learning (i.e., 'The structure of learning to foster motivation and engagement'), whereas the word 'motivated' referred to factors outside of academic motivation, such as 'staff are passionate, highly motivated and professional'. We removed 'motivated' and other ambiguous words, resulting in a final list of 39, 40 , and 24 words and phrases respectively in the academic motivation, mental health promotion, and school belonging lexica (see Supplement S1 for final lexica and the relative frequency that each occurred).

Using the resulting lexica, we processed the statements using NVivo 10 for Windows (2014), a Computer Aided Qualitative Data Analysis System (Richards, 2005). ${ }^{1}$ First, all words in the statements were indexed and tabulated with frequencies and synonyms and compared to the lexica to ensure no variation of relevant words had been overlooked. Next, computer-generated text searches found every word and phrase in the lexica and coded all mentions to nodes, which were organised into a thematic structure in line with the lexica themes. These nodes, which contained all references to key words and phrases, were then placed in a matrix intersecting them with all cases (schools). The results of these matrix-coding queries were then exported to an Excel table that contained the absolute frequencies, number of words, and relative frequencies (i.e., frequency adjusted by the number of words), separated by school. As frequencies had many zero values and were rightly skewed, we also computed a dichotomous indicator of each theme being present (coded 1) or absent (coded 0$)$.

Data Analyses

The qualitative (emergent coding) approach produced dichotomous indicators of each theme being present, and the quantitative (supervised lexical) approach 
produced the continuous relative frequency and a dichotomous indicator of each theme being present. We first compared achievement scores across the six dichotomous variables using $t$ tests. Second, we calculated correlations between the three continuous frequency variables and the mean NAPLAN scores, separately for Year 7 and Year 9 students, using Spearman's rank order correlations. We also regressed Year 7 or Year 9 achievement scores on the relative frequency of the three themes, testing the unique contribution of each them when controlling for the other two. Finally, to consider the potential value of including MHP and school belonging along with academic motivation, for schools that included academic motivation, $t$ tests compared: (1) MHP present or absent, (2) school belonging present or absent, and (3) both MHP and school belonging present versus both being absent.

NAPLAN scores for a school represent the average scores of the students at the school. Unless student performance is homogenous, such estimates are more precise with larger sample sizes. School sizes ranged from 5 to 630 , and thus unweighted correlations may overestimate effects in small schools and underestimate effects in large schools. To consider the robustness of estimates, analyses were first conducted at the school level (i.e., $\mathrm{K}=$ the number of schools), and then repeated weighting by the number of students $(n)$ within the school.

$T$ test, correlation, and regression analyses were performed using IBM SPSS Statistics (Version 22.0) software. We applied bootstrapping to the analyses, and include the $95 \%$ confidence intervals around the correlation coefficients or mean difference scores. ${ }^{2}$

\section{Results}

Table 1 summarises descriptive information. Across methods, academic motivation was the most common theme, occurring in $87.5 \%$ and $73.9 \%$ of the statements for the two coding approaches respectively. School belonging was consistent across the two approaches (59.2\% vs. $55.1 \%$ ), appearing in just over half of the statements. MHP was less consistent across the two coding approaches, with the emergent coding approach identifying the presence of MHP in the statement almost twice as often as the lexical approach ( $67.2 \%$ vs. $35.2 \%$ of school statements).

Across both qualitative and quantitative coding approaches, achievement was negatively related to academic motivation and school belonging (see Table 2$){ }^{3}$ In contrast, for MHP, the qualitative approach indicated a negative association with achievement, Year 7: $t(33,923)=-15.60, p<.001$; Year 9: $t(32,407)=-19.59, p<.001$, whereas the quantitative approach indicated a positive association, Year $7: t(33,923)=12.58$, $p<.001$; Year 9: $t(32,407)=15.31, p<.001$. Results were consistent across Year 7 and Year 9, with MHP having a stronger effect in Year 9 than in Year 7. Correlation and regression analyses with the continuous relative frequency variables followed the same pattern of results (see Supplement Tables S3 and S4), with academic motivation and school belonging negatively related to academic achievement and MHP positively related to academic achievement.

Finally, we considered the potential added benefit of including MHP and school belonging (i.e., social and emotional themes) versus only academic motivation (i.e., a cognitive theme; see Supplemental Table S5). School belonging related to lower achievement scores in both the qualitative approach, Year 7: $t(29,527)=-8.69, p<$ .001 ; Year 9: $t(28,239)=-4.46, p<.001$, and the lexical approach, Year 7: $t(25,881)$ 
TABLE 1

Descriptive Statistics for Language and Achievement Data

\begin{tabular}{|c|c|c|c|c|c|}
\hline Variable & $N$ & Mean & $S D$ & Min & Max \\
\hline \multicolumn{6}{|l|}{ Unweighted estimates } \\
\hline \multicolumn{6}{|l|}{ Qualitative ratings (dichotomous) } \\
\hline Academic motivation & 287 & 0.88 & 0.33 & 0.00 & 1.00 \\
\hline Mental health promotion & 287 & 0.67 & 0.47 & 0.00 & 1.00 \\
\hline School belonging & 287 & 0.59 & 0.49 & 0.00 & 1.00 \\
\hline \multicolumn{6}{|l|}{ Lexical Approach } \\
\hline Relative frequency (continuous) & 287 & 0.03 & 0.03 & 0.00 & 0.17 \\
\hline Academic motivation & 287 & 0.01 & 0.03 & 0.00 & 0.19 \\
\hline Mental health promotion & 287 & 0.01 & 0.02 & 0.00 & 0.08 \\
\hline \multicolumn{6}{|l|}{ School belonging } \\
\hline \multicolumn{6}{|l|}{ Theme present (dichotomous) } \\
\hline Academic motivation & 287 & 0.74 & 0.44 & 0.00 & 1.00 \\
\hline Mental health promotion & 287 & 0.35 & 0.48 & 0.00 & 1.00 \\
\hline School belonging & 287 & 0.55 & 0.50 & 0.00 & 1.00 \\
\hline \multicolumn{6}{|l|}{ Achievement scores (continuous) } \\
\hline Year 7 & 278 & 542.26 & 30.01 & 472.00 & 635.40 \\
\hline Year 9 & 277 & 578.19 & 33.14 & 480.26 & 673.00 \\
\hline \multicolumn{6}{|c|}{ Estimates weighted by number of students } \\
\hline \multicolumn{6}{|l|}{ Qualitative ratings (dichotomous) } \\
\hline Academic motivation & 34,409 & 0.87 & 0.33 & 0.00 & 1.00 \\
\hline Mental health promotion & 34,409 & 0.68 & 0.47 & 0.00 & 1.00 \\
\hline School belonging & 34,409 & 0.59 & 0.49 & 0.00 & 1.00 \\
\hline \multicolumn{6}{|l|}{ Lexical Approach } \\
\hline \multicolumn{6}{|l|}{ Relative frequency (continuous) } \\
\hline Academic motivation & 34,409 & 0.03 & 0.03 & 0.00 & 0.17 \\
\hline Mental health promotion & 34,409 & 0.01 & 0.03 & 0.00 & 0.19 \\
\hline School belonging & 34,409 & 0.01 & 0.01 & 0.00 & 0.08 \\
\hline \multicolumn{6}{|l|}{ Theme present (dichotomous) } \\
\hline Academic motivation & 34,409 & 0.77 & 0.42 & 0.00 & 1.00 \\
\hline Mental health promotion & 34,409 & 0.39 & 0.49 & 0.00 & 1.00 \\
\hline School belonging & 34,409 & 0.57 & 0.50 & 0.00 & 1.00 \\
\hline \multicolumn{6}{|l|}{ Achievement scores (continuous) } \\
\hline Year 7 & 33,925 & 546.50 & 29.57 & 472.00 & 635.40 \\
\hline Year 9 & 32,409 & 582.51 & 33.13 & 480.26 & 673.00 \\
\hline
\end{tabular}

$=-12.69, p<.001$; Year 9: $t(24,613)=-6.55, p<.001$. Again, MHP depended on coding approach; the qualitative approach suggested a negative association between academic achievement and mental health promotion, Year 7: $t(29,527)=-2.40, p$ $=.02$; Year 9: $t(28,239)=-4.97, p<.001$, whereas the lexical approach suggested a positive association, Year 7: $t(25,881)=8.98, p<.001$; Year 9: $t(24,613)=9.11, p<.001$.

\section{Discussion}

This study investigated the relationship between the extent to which schools explicitly prioritise academic motivation, mental health promotion, and school belonging in their values and mission statements and an objective measure of a school's average academic achievement, using two approaches for coding themes (emergent coding and supervised lexical analysis). Including academic motivation or school belonging 
TABLE 2

$T$ Tests for Dichotomous Variables (Indicating Theme was Included or Not, Using Qualitative and Lexical Coding Approaches) and Achievement Scores (Weighted by the Number of Studies; see Supplement S2 for Unweighted Estimates)

\begin{tabular}{|c|c|c|c|c|c|c|c|c|c|c|c|c|c|c|}
\hline & \multicolumn{3}{|c|}{ Included theme } & \multicolumn{3}{|c|}{ Did not include theme } & \multirow[b]{2}{*}{ MD } & \multirow[b]{2}{*}{$S E$} & \multirow{2}{*}{\multicolumn{2}{|c|}{$95 \% \mathrm{Cl}$}} & \multirow[b]{2}{*}{$t$} & \multirow[b]{2}{*}{$d f$} & \multirow[b]{2}{*}{$p$} & \multirow[b]{2}{*}{$r$} \\
\hline & $n$ & $M$ & $S D$ & $n$ & $M$ & $S D$ & & & & & & & & \\
\hline \multicolumn{15}{|l|}{ Year 7} \\
\hline \multicolumn{15}{|l|}{ Qualitative ratings } \\
\hline Academic motivation & 29,529 & 545.06 & 29.60 & 4,396 & 556.15 & 27.53 & -11.09 & .45 & -11.94 & -10.18 & -23.38 & 33,923 & .001 & -.13 \\
\hline Mental health promotion & 23,491 & 544.83 & 28.48 & 10,434 & 550.24 & 31.57 & -5.41 & .37 & -6.11 & -4.67 & -15.60 & 33,923 & .001 & -.08 \\
\hline School belonging & 20,002 & 544.24 & 26.56 & 13,923 & 549.75 & 33.16 & -5.51 & .35 & -6.19 & -4.81 & -16.95 & 33,923 & .001 & -.09 \\
\hline Lexical approach & & & & & & & & & & & & & .001 & \\
\hline Academic motivation & 25,883 & 545.47 & 29.34 & 8,042 & 549.82 & 30.05 & -4.35 & .39 & -5.08 & -3.53 & -11.55 & 33,923 & .001 & -.06 \\
\hline Mental health promotion & 13,384 & 548.99 & 28.58 & 20,541 & 544.87 & 30.09 & 4.12 & .33 & 3.48 & 4.77 & 12.58 & 33,923 & .001 & .07 \\
\hline School belonging & 19,221 & 544.32 & 27.62 & 14,704 & 549.35 & 31.72 & -5.03 & .32 & -5.68 & -4.39 & -15.58 & 33,923 & .001 & -.08 \\
\hline \multicolumn{15}{|l|}{ Year 9} \\
\hline \multicolumn{15}{|l|}{ Qualitative ratings } \\
\hline Academic motivation & 28,241 & 580.96 & 33.33 & 4,168 & 593.01 & 29.65 & -12.05 & .50 & -13.07 & -11.02 & -22.08 & 32,407 & .001 & -.12 \\
\hline Mental health promotion & 21,764 & 580.01 & 31.20 & 10,645 & 587.64 & 36.23 & -7.63 & .41 & -8.44 & -6.86 & -19.59 & 32,407 & .001 & -.11 \\
\hline School belonging & 19,224 & 580.57 & 31.09 & 13,185 & 585.35 & 35.71 & -4.78 & .39 & -5.56 & -4.00 & -12.78 & 32,407 & .001 & -.07 \\
\hline Lexical approach & & & & & & & & & & & & & .001 & \\
\hline Academic motivation & 24,615 & 581.54 & 33.19 & 7,794 & 585.58 & 32.74 & -4.03 & .43 & -4.90 & -3.20 & -9.38 & 32,407 & .001 & -.05 \\
\hline Mental health promotion & 12,062 & 586.16 & 30.67 & 20,347 & 580.35 & 34.32 & 5.81 & .37 & 5.08 & 6.53 & 15.31 & 32,407 & .001 & .08 \\
\hline School belonging & 18,212 & 581.03 & 32.16 & 14,197 & 584.41 & 34.24 & -3.38 & .38 & -4.06 & -2.62 & -9.12 & 32,407 & .001 & -.05 \\
\hline
\end{tabular}

Note. $\mathrm{MD}=$ mean difference, $\mathrm{SE}=$ standard error, $\mathrm{Cl}=$ confidence interval. Mean difference and $95 \%$ confidence intervals based on 1000 bootstrapped samples. 
related to lower academic performance. Results were less consistent for MHP, with the emergent coding approach suggesting a negative association between MHP and performance and the lexical analysis suggesting a positive association.

It is well established in the literature that the variables addressed in this study academic motivation, MHP, and school belonging — are related to positive academic benefits for secondary school students at the individual level of analysis, but less is known at the collective level. School leaders play an important role in creating a school culture that is more or less supportive of achievement, belonging, and wellbeing, but it is challenging to determine the impact of different priorities and decisions. Although VMSs are often viewed as pivotal for guiding school policy and procedures (e.g., Allen, Vella-Brodrick et al., 2016; Allen, Kern et al., 2016 Stemler \& Bebell, 1999; Stemler et al., 2011), only a limited number of studies have compared these statements with academic outcomes (e.g., Brown et al., 2011; Davis et al., 2007).

Aspects of the implicit and explicit school culture are often hard to capture quantitatively and are thus ignored. The current study began with qualitative information - VMSs - and tested two approaches for quantitatively encoding the information. For academic motivation and school belonging, the two encoding approaches were comparable. Across methods, there was a negative association between academic scores and academic motivation and school belonging. This differs from other studies that found VMSs to be effective in influencing student character traits (Davis et al., 2007). These results also differ from previous findings at the student level that have shown the importance of academic motivation and school belonging for achievement (Anderman, 2002; Booker, 2007; DiPerna et al., 2002; Robbins et al., 2004; Sanchez, Col'on, \& Esparza, 2005; Walton \& Cohen, 2011). It is possible that this is a true association, characteristic of Australian schools, compared to studies conducted in other countries. Alternatively, this association might be driven by the high percentage of schools that included academic motivation as a theme. It may be that not including the theme is problematic, but once included, a higher frequency does not add any additional benefit.

In contrast, the two approaches differed substantially in identifying the MHP theme, and this corresponded with different associations with academic achievement. The lexical approach suggested that MHP was related to higher NAPLAN scores. This finding supports past research, which has found mental health promotion to be important for student achievement (Greenberg et al., 2003; Zins et al., 2004). The correlation was slightly stronger in Year 9 than in Year 7, suggesting an increasing impact as students are in the school for a longer period of time. However, the emergent coding approach suggested an inverse association. The lexical approach was considerably more conservative in nature. It is unclear which approach is more accurate; the linguistic analyses add an alternative method for educational research, but they also add an additional layer of complexity. As technology continues to evolve, it will be increasingly possible to automate the coding of qualitative information. The results here suggest that the approach used can have an impact on the findings, and future research should continue to carefully evaluate the impact of different coding procedures.

At the collective level, it is also unclear what degree of aggregation should occur. Results were consistent across the weighted and unweighted estimates, but the weighted estimates offered greater precision. NAPLAN scores represent the average of the students at the school, and although it provides a simple aggregate measure 
of performance, it also obscures individual variation. The extent to which a school prioritises academic motivation, mental health promotion, and school belonging may have more of an impact for some students versus others. Further, the extent to which schools live out their explicit values in the day-to-day function of the school is unknown, as is the impact of socioeconomic status. Unfortunately, we did not have such data available, and future research will benefit from considering the moderating effect of socioeconomic status, gender, context, and other variables of interest.

\section{Implications}

The field of educational and developmental psychology focuses not only on the individuals within the school community, but also the broader systems and structures of schools. A goal therefore of educational and developmental psychologists is to advocate for the promotion of educational standards and goals, along with the policies and procedures needed to achieve them (Aslanargun, 2007). It is important for educational and developmental psychologists to consider all features of a school's system, including VMSs, when promoting wellbeing initiatives at a whole-school level. Designing a VMS for the purpose of improved student outcomes is an important topic of enquiry in educational settings. This study suggests that including MHP within statements may also be beneficial.

VMSs have been used as a social marketing tool for schools, which is also a central element of successful public health change programs (Donovan, 2011). VMSs may serve as a public declaration of valuing mental health. They may also be used to encourage individuals to adopt healthy behaviours. Regardless of the correlations with academic performance, they are an important part of the broader purposes of education. VMSs help create the climate of the school, and send a message to students, staff, and the broader school community that mental health and other aspects of the whole student are important to the school.

\section{Limitations}

The practical value of these findings should be interpreted with caution. Research that has investigated whether VMSs have a tangible impact in the school related to what they espouse is mixed (Gioia, Nag, \& Corley, 2012). We could not determine the extent to which the schools were living up to their VMS. It may be that including such themes in the mission statement only matter to the extent to which curriculum, programs, and strategies actually promote these themes in the school. Further, it is unclear whether school VMSs result in actual cognitions and behaviours at the student level. Future research may wish to understand the extent to which the themes that are included in a school's VMS are put into practice.

We also could not determine how long the school had been using their current VMS. As it takes time for changing values to trickle down through the school, statements that have been around for longer most likely have a greater influence on how students function and feel than new statements, but the time it takes for changes in a statement to have an impact on the culture and practices of a school is unknown. Alternatively, a new vision statement could have a greater impact if it significantly disrupts traditions or is driven by a charismatic leader. Future studies might examine the extent to which VMSs drive stability or change in the school's culture.

In this study, we only focused on academic performance, operationalised through NAPLAN scores as the outcome of interest. While the current educational climate 
stresses the value of standardised test scores, many would argue that the goal of education goes well beyond academic performance, and includes developing the character and social and emotional health of young people (e.g., Seligman, Ernst, Gillham, Reivich, \& Linkins, 2009). Future research might consider how different themes link to alternative outcomes, such as student wellbeing, psychosocial maturity, and behavioural measures (e.g., detentions, classroom behaviour, school dropout).

The small effect sizes must be acknowledged. Although the patterns across multiple analytic methods provide support for the benefits of focusing the school's mission on aspects separate from academics, a multitude of factors have an impact on academic performance. Still, effect sizes were similar to other studies examining associations between language and other characteristics (e.g., Kern et al., 2014). Further, even small effect sizes can have an important impact when considered across tens of thousands of individuals (see Meyer et al., 2001, for comparison). For example, the impact of divorce on a child's wellbeing reports a very weak effect size of .09 , yet most schools would ensure appropriate support and intervention is in place given the circumstances (Meyer et al., 2001).

\section{Conclusion}

This study aimed to assess the endorsement of academic motivation, MHP, or school belonging in school VMSs and the relationship with student academic achievement. Despite the cautions surrounding the correlations, this study provides a methodological contribution to future research by introducing the use of language analysis as a tool for future researchers to use when investigating multilevel constructs in schools. VMSs allow schools to express the goals and aspirations for which the school may aspire to and make a public statement of what the school values. Still, the values expressed in a statement alone are insufficient; efforts by school leaders and educational and developmental psychologists should occur at multiple socio-ecological levels to have the greatest positive impact on student wellbeing and achievement.

\section{Financial Support}

This work did not receive financial support.

\section{Conflict of Interest}

None.

\section{Ethical Standards}

This review did not involve human and/or animal experimentation.

\section{Supplementary Material}

To view supplementary material for this article, please visit https://doi.org/10. 1017/edp.2017.5.

\section{Endnotes}

1 LIWC allows users to take a set of text and calculate the relative frequency that each dictionary occurs. New dictionaries, such as those we created here, can be added using the LIWC 
infrastructure. While this automatic process speeds up the coding process, it can also result in many false positives (words and phrases are present but represent the wrong context) and false negatives (missing relevant words that were not included in the lexica). To minimise automatic errors, we chose to use NVivo for processing the data, allowing us to consider the context that words and phrases occurred.

2 It is unclear what statistical significance means in this context. Language is noisy, such that the unweighted estimates are often not powerful enough to detect significance with language, whereas with very large samples, most estimates will be statistically significant but not necessarily meaningful (Kern et al., 2016). Bootstrapping provides an estimate of accuracy of the effects and indicates the stability of the results. Thus, we focus on effect sizes and confidence intervals and the pattern of results rather than on significance testing, but also report $p$ values for completeness.

3 The general patterns and effect sizes were consistent in both the weighted and unweighted estimates, although for the unweighted estimates, confidence intervals are wide, suggesting less accuracy in the estimates, so we focus on the weighted estimates here (see Supplement tables for unweighted estimates).

\section{References}

Allen, K., \& McKenzie, V. (2015). Mental health in an Australian context and future interventions from a school belonging perspective. Special Issue on Mental Health in Australia for the International Journal of Mental Health, 44, 80-93. doi:10.1080/00207411.2015

Allen, K.A., Vella-Brodrick, D., \& Waters, L. (2016). Fostering school belonging in secondary schools using a socio-ecological framework. The Educational and Developmental Psychologist, 33, 97-121. doi:10.1177/0042085902371004

Allen, K., Kern, P., Vella-Brodrick, D., Hattie, J., \& Waters, L. (2016). What schools need to know about belonging: A meta-analysis. Educational Psychology Review, 1-34. doi:10.1007/s10648-016-9389-8

Allen, K.A., Kern, M.L., Waters, L., \& Vella-Brodrick, D. (2016). Understanding a school's priorities through analysis of their mission and vision statements. Unpublished manuscript.

Anderman, E.M. (2002). School effects on psychological outcomes during adolescence. Journal of Educational Psychology, 94, 795-809. doi:10.1037/0022-0663.94.4.795

Anderson, J. (2009). Using NAPLAN Items to: Develop students' thinking skills and build confidence. Australian Mathematics Teacher, 65, 17-23.

Aslanargun, E. (2007). The critics of modern educational administration and postmodern educational administration. Educational Administration: Theory and Practice, 50, 195-212.

Australian Curriculum, Assessment and Reporting Authority (ACARA). (2008). NAPLAN. Sydney, Australia: Author. Retrieved from http://www.nap.edu.au/naplan/naplan.html

Battistich, V., Solomon, D., Kim, D., Watson, M., \& Schaps, E. (1995). Schools as communities, poverty levels of student populations, and students' attitudes, motives, and performance: A multilevel analysis. American Educational Research Journal, 32, 627-658. doi:10.2105/AJPH.87.12.1997

Benner, A.D., Graham, S., \& Mistry, R.S. (2008). Discerning direct and mediated effects of ecological structures and processes on adolescents' educational outcomes. Developmental Psychology, 44, 840. doi:10.1037/0012-1649.44.3.840

Boerema, A.J. (2006). An analysis of private school mission statements. Peabody Journal of Education, 81, 180-202. doi:10.1207/S15327930pje8101_8

Bonny, A.E., Britto, M.T., Klostermann, B.K., Hornung, R.W., \& Slap, G.B. (2000). School disconnectedness: Identifying adolescents at risk. Pediatrics, 106, 1017-1021. doi:10.1348/000709909X484479

Booker, K.C. (2007). Likeness, comfort and tolerance: Examining African American adolescents' sense of school belonging. Urban Review, 38, 301-317. doi:10.1007/s11256-007-0053-y

Brown, G., \& Hattie, J. (2012). The benefits of regular standardized assessment in childhood education: Guiding improved instruction and learning. In S. Suggate \& E. Reese (Eds.), Contemporary debates in childhood education and development (pp. 287-292). London: Routledge. 
Brown, S., Choi, K., \& Herman, B. (2011). Exploratory study of the HOPE Foundation Courageous Leadership Academy: Summary of findings. Washington, DC: American Institutes for Research.

Chapple, J. (2015). Mission Accomplished? School mission statements in NZ and Japan: What they reveal and conceal. Asia Pacific Educational Review, 16, 137-147. doi:10.1007/s12564-015-9360-2

Collaborative for Academic, Social, and Emotional Learning (CASEL). (2007). Background on social and emotional learning. Retrieved from www.casel.org/downloads/SEL\&CASELbackground.pdf

Comber, B. (2012). Mandated literacy assessment and the reorganisation of teachers' work: Federal policy, local effects. Critical Studies in Education, 53, 119-136. doi:10.1080/17508487.2012.672331

Comber, B., \& Nixon, H. (2009). Teachers' work and pedagogy in an era of accountability. Discourse: Studies in the Cultural Politics of Education, 30, 333-345. doi:10.1080/01596300903037069

Connell, J.P., \& Wellborn, J.G. (1991). Competence, autonomy and relatedness: A motivational analysis of self-system processes. In M.R. Gunnar \& L.A. Sroufe (Eds.), Minnesota Symposium on Child Psychology (pp. 43-77). Hillsdale, MI: Lawrence Erlbaum Associates.

Croninger, R.G., \& Lee, V.E. (2001). Social capital and dropping out of high school: Benefits to at-risk students of teachers' support and guidance. Teachers College Record, 103, 548-581.

Davis, J., Ruhe, J., Lee, M., \& Rajadhyaksha, U. (2007). Mission possible: Do school mission statements work? Journal of Business Ethics, 70, 99-110. doi:10.1007/s10551-006-9076-7

DiPerna, J., Volpe, R., \& Elliott, S. (2002). A model of academic enablers and elementary reading/language arts achievement. School Psychology Review, 31, 298-312.

Dix, K.L., Slee, P.T., Lawson, M.J., \& Keeves, J.P. (2012). Implementation quality of whole school mental health promotion and students' academic performance. Child and Adolescent Mental Health, 17, 45-51. doi:10.1111/j.1475-3588.2011.00608.x

Donovan, J. (2011). The role for marketing in public health change programs. Australian Review of Public Affairs, 10, 23-40. doi:10.1111/j.1475-3588.2011.00608.x

Donovan, R.J., James, R., Jalleh, G., Sidebottom, C. (2006). Implementing mental health promotion: The Act-Belong-Commit Mentally Healthy WA Campaign in Western Australia. International Journal of Mental Health Promotion, 8, 33-42. doi:10.1111/1753-6405.12514

Durlak, J.A., Weissberg, R.P., Dymnicki, A.B., Taylor, R.D., \& Schellinger, K.B. (2011). The impact of enhancing students' social and emotional learning: A meta-analysis of school- based universal interventions. Child Development, 82, 405-432. doi:10.1111/j.1467-8624.2010.01564.x.

Fritz, A. (1996). Reflective practice: Enhancing the outcomes of technology learning experiences. Journal of Design and Technology Education, 1, 212-217.

Gioia, D.A., Nag, R., \& Corley, K.G. (2012). Visionary ambiguity and strategic change: The virtue of vagueness in launching major organizational change. Journal of Management and Inquiry, 21, 364375.

Gillen-O’Neel, C., \& Fuligni, A. (2013). A longitudinal study of school belonging and academic motivation across high school. Child Development, 84, 678-692. doi:10.1111/j.1467-8624.2012.01862.x

Greenberg, M.T., Weissberg, R.P., O’Brien, M.U., Zins, J.E., Fredericks, L., Resnick, H., \& Elias, M.J. (2003). Enhancing school-based prevention and youth development through coordinated social, emotional, and academic learning. American Psychologist, 58, 466-474. doi:10.1037/0003-066X.58.6-7.466

Guenther, J. (2013, December). Towards educational advantage in very remote Australia: An analysis of 2012 NAPLAN data: What does it tell us about remote education in the last five years. Paper presented at the Australian Association for Research in Education, Adelaide, Australia.

Hardy, I., \& Boyle, C. (2011). My School? Critiquing the abstraction and quantification of education. AsiaPacific Journal of Teacher Education, 39, 211-222. http://dx.doi.org/10.1080/1359866X.2011.588312

Holmes, S. (2010). No child left behind: A failing attempt at reform. Student Pulse, 2(12).

Jones, L., \& Crochet, F. (2007). The importance of visions for schools and school improvement. Journal of Research in Educational Psychology, 9, 463-496.

Kern, M.L., Park, G., Eichstaedt, J.C., Schwartz, H.A., Sap, M., Smith, L.K., \& Ungar, L.H. (2016). Gaining insights from social media language: Methodologies and challenges. Psychological Methods, 21, 507525. doi:10.1037/met0000091 
Kern, M.L., Eichstaedt, J.C., Schwartz, H.A., Dziurzynski, L., Ungar, L.H., Stillwell, D.J., ... Seligman, M.E. (2014). The online social self: An open vocabulary approach to personality. Assessment, 21, 158-169. doi:10.1177/1073191113514104

Klem, A.M., \& Connell, J.P. (2003, June). Relationships matter: Linking teacher support to student engagement and achievement. Paper presented at the Wingspread Conference on School Connectedness, Racine, WI.

Kobau, R., Seligman, M., Peterson, C., Diener, E., Zack, M., Chapman, D., \& Thompson, W. (2011). Mental health promotion in public health: perspectives and strategies from positive psychology. American Journal of Public Health, 101, e1-e9. doi:10.2105/AJPH.2010.30008

Lee, J.Q., McInerney, D.M., Liem, G.A.D., \& Ortiga, Y.P. (2010). The relationship between future goals and achievement goal orientations: An intrinsic-extrinsic motivation perspective. Contemporary Educational Psychology, 35, 264-279. doi:10.1016/j.cedpsych.2010.04.004

Libbey, H.P. (2004). Measuring student relationships to school: Attachment, bonding, connectedness, and engagement. Journal of School Health, 74, 275-283. doi: 10.1111/j.1746-1561.2004.tb08284.x

Lingard, B. (2010). Policy borrowing, policy learning: testing times in Australian schooling. Critical Studies in Education, 51, 129-145.

Manley, R.J., \& Hawkins, R.J. (2009). Designing school systems for all students: A toolbox to fix America's schools. R\&L Education. Retrieved from https://books.google.com.au/books/about/ Designing_School_Systems_for_All_Student.html?id=LZl3cVzZpHUC\&hl=en

McMillan, J.H. (2000). Fundamental assessment principles for teachers and school administrators. Practical Assessment, Research \& Evaluation, 7, 1-9.

Meyer, G.J., Finn, S.E., Eyde, L.D., Kay, G.G., Moreland, K.L., Dies, R.R., . . R Reed, G.M. (2001). Psychological testing and psychological assessment: A review of evidence and issues. American Psychologist, 56, 128-165. doi:10.1037/0003-066X.56.2.128

Miller, P.W., \& Voon, D. (2012). Government versus non-government schools: A nation-wide assessment using Australian NAPLAN data. Australian Economic Papers, 51, 147-166.

Mo, Y., \& Singh, K. (2008). Parents' relationships and involvement: Effects on students' school engagement and performance. Research in Middle Level Education Online, 31, 1-11.

Payton, J., Weissberg, R., Durlak, J., Dymnicki, A., Taylor, R., Schellinger, K., \& Pachan, M. (2008). The positive impact of social and emotional learning for kindergarten to eighth-grade students. Chicago, IL: Collaborative for Academic, Social, and Emotional Learning.

Pennebaker, J., Chung, C., Ireland, M., Gonzales, A., \& Booth, R. (2007). The development and psychometric properties of LIWC2007. Austin, TX: LIWC.net.

Polesel, J., Dulfer, N., \& Turnbull, M. (2012). The experience of education: The impacts of high stakes testing on school students and their families - Literature review. Sydney, Australia: The Whitlam Institute.

Pollock, K., \& Winton, S. (2012). School improvement: A case of competing priorities. Journal of Cases in Educational Leadership, 15, 11-21. doi:10.1177/1555458912447840

Quinell, L., \& Carter, L. (2011). Cracking the language code: NAPLAN numeracy tests in years 7 and 9. Literacy Learning: The Middle Years, 19, 45-53.

Quinlan, D.M., Swain, N., Cameron, C., \& Vella-Brodrick, D. (2014): How 'other people matter' in a classroom-based strengths intervention: Exploring interpersonal strategies and classroom outcomes. The Journal of Positive Psychology, 10, 77-89. doi:10.1080/17439760.2014.920407

Richards, L. (2005). Handling qualitative data: A practical guide. London, England: Sage.

Rickwood, D. (2007). Conceptual framework for PPEI and applications in general practice: Overview of the literature. [Monograph]. In A. O’Hanlon, A. Patterson, \& J. Parham (Eds.), Promotion, prevention and early intervention for mental health in general practice. Adelaide, Australia: Australian Network for Promotion, Prevention and Early Intervention for Mental Health.

Reitzner, M. (2014). Signature well-being: Toward a more precise operationalization of well-being at the individual level (Unpublished master's thesis). University of Pennsylvania, Philadelphia, PA.

Robbins, S.B., Lauver, K., Le, H., Davis, D., Langley, R., \& Carlstrom, A. (2004). Do psychosocial and study skill factors predict college outcomes? A meta-analysis. Psychological Bulletin, 130, 261-288. doi:10.1037/0033-2909.130.2.261 
Roeser, R.W., Midgley, C., \& Urdan, T.C. (1996). Perceptions of the school psychological environment and early adolescents' psychological and behavioral functioning in school: The mediating role of goals and belonging. Journal of Educational Psychology, 88, 408-422. doi:10.1037/0022-0663.88.3.408

Ryan, R.M., \& Deci, E.L. (2000). Self-determination theory and the facilitation of intrinsic motivation, social development, and wellbeing. American Psychologist, 55, 68-78. doi:10.3102/00028312038002437

Sanchez, B., Col'on, Y., \& Esparza, P. (2005). The role of sense of school belonging and gender in the academic adjustment of Latino adolescents. Journal of Youth and Adolescence, 34, 619-628. doi:10.1007/s10964-005-8950-4

Seligman, M.E., Ernst, R.M., Gillham, J., Reivich, K., \& Linkins, M. (2009). Positive education: Positive psychology and classroom interventions. Oxford Review of Education, 35, 293-311. doi:10.1080/ 03054980902934563

Sirin, S.R., \& Rogers-Sirin, L. (2004). Exploring school engagement of middle-class African American adolescents. Youth \& Society, 35, 323-340. doi:10.1177/0044118X03255006

Sirin, S.R., \& Rogers-Sirin, L. (2005). Components of school engagement among African American adolescents. Applied Developmental Science, 9, 5-13. doi:10.1207/s1532480xads0901_2

Slee, P., Lawson, M., Russell, A., Askell-Williams, H., Dix, K., Owens, L., ... Spears, B. (2009). KidsMatter Primary Evaluation final report. Melbourne, Australia: beyondblue. Retrieved from https://www.kidsmatter.edu.au/sites/default/files/public/kidsmatter-full-report-web.pdf

Stemler, S., \& Bebell, D. (1999). An empirical approach to understanding and analyzing the mission statements of selected educational institutions. Paper presented at the Annual Meeting of the New England Educational Research Organization (NEERO), Portsmouth, New Hampshire.

Stemler, S., Bebell, D., \& Sonnabend, L.A. (2011). Using school mission statements for reflection and research. Educational Administration Quarterly, 47, 383-420. doi:10.1177/0013161X10387590

Swearer, S., Peugh, J., Espelage, D., Siebecker, A., Kingsbury, W., \& Bevins, K. (2006). A socioecological model for bullying prevention and intervention in early adolescence: An exploratory examination. In S.R. Jimerson \& M.J. Furlong (Eds.), Handbook of school violence and school safety: From research to practice (pp. 257-273). Mahwah, NJ: Erlbaum.

Tella, A. (2007). The impact of motivation on student's academic achievement and learning outcomes in mathematics among secondary school students in Nigeria. Eurasia Journal of Mathematics, Science \& Technology Education, 3, 149-156. doi:10.12973/eurasia.2007.00051a

Thompson, G. (2013). NAPLAN, My School and Accountability: Teacher perceptions of the effects of testing. The International Education Journal: Comparative Perspectives, 12, 62-84.

Thompson, G., \& Cook, I. (2014). Manipulating the data: Teaching and NAPLAN in the control society. Discourse: Studies in the Cultural Politics of Education, 35, 129-142. doi:10.1080/01596306.2012.739472

Volante, L. (2004). Teaching to the test: What every educator and policy-maker should know. Canadian Journal of Educational Administration and Policy, 35.

Walton, G.M., \& Cohen, G.L. (2011). A brief social-belonging intervention improves academic and health outcomes of minority students. Science Journal, 331, 1447-1451. doi:10.1126/science.1198364

Wigglesworth, G., Simpson, J., \& Loakes, D. (2011). NAPLAN language assessments for Indigenous children in remote communities: Issues and problems. Australian Review of Applied Linguistics, 34, 320-343.

Wilkerson, K. (2010). School counselor reform and principal's priorities: A preliminary content analysis of the National Association for Secondary School Principals (NASSP) Bulletin (1997-2007) informed by guiding documents of the American School Counselor Association (ASCA). Education, 131, 419-436.

Wilkinson-Lee, A.M., Zhang, Q., Nuno, V.L., \& Wilhelm, M.S. (2011). Adolescent emotional distress: The role of family obligations and school connectedness. Journal of Youth and Adolescence, 40, 221-230. doi:10.1007/s10964-009-9494-9

Wingspread Declaration on School Connections. (2004). Journal of School Health, 74, 233-234.

Zins, J., Weissberg, R., Wang, M., \& Walberg, H. (Eds). (2004). Building academic success on social and emotional learning: What does the research say? New York, NY: Teachers College Press. 